Check for updates

Cite this: RSC Adv., 2018, 8, 32922

\title{
The activity and stability of $\mathrm{CeO}_{2} \mathrm{aCaO}$ catalysts for the production of biodiesel $\uparrow$
}

\author{
Ni Zhang, Huiyuan Xue and Rongrong Hu (D) *
}

A novel $\mathrm{CeO}_{2} \mathrm{QCaO}$ catalyst was prepared via a hydrothermal method. The physicochemical properties and morphologies of the prepared $\mathrm{CeO}_{2} \mathrm{aCaO}$ catalysts were characterized by X-ray diffraction, $\mathrm{N}_{2}$ physisorption, $\mathrm{CO}_{2}$ temperature-programmed desorption, X-ray photoelectron spectroscopy, transmission electron microscopy and energy dispersive $\mathrm{X}$-ray analysis. It was found that the prepared $\mathrm{CeO}_{2} \mathrm{aCaO}$ catalyst had a distinct core-shell structure. The catalytic activity of the $\mathrm{CeO}_{2} @ \mathrm{aCaO}$ sample as a heterogeneous catalyst for the transesterification of soybean oil to produce biodiesel has been studied. The results showed that the optimum yield of biodiesel can reach $98 \%$ over the $\mathrm{CeO}_{2} \mathrm{QCaO}-60$ catalyst under the reaction conditions of $3 \mathrm{wt} \%$ catalyst, methanol to oil molar ratio of $6: 1$, reaction temperature of $70{ }^{\circ} \mathrm{C}$ and reaction time of $6 \mathrm{~h}$. Stability tests indicated that the biodiesel yield can reach more than $80 \%$ even after 9 reaction cycles due to the strong synergic interaction between $\mathrm{CaO}$ and $\mathrm{CeO}_{2}$.

Received 17th August 2018

Accepted 11th September 2018

DOI: $10.1039 / \mathrm{c} 8 \mathrm{ra06884d}$

rsc.li/rsc-advances

such as easily separated, reusable, and free from saponification

\section{Introduction}

As is well known, due to the shortage of fossil fuels, environmental pollution and ecological deterioration, people have turned their attention to low-carbon, environmentally friendly, clean and safe renewable resources. Biodiesel has received increasing attention in recent years since it is renewable, biodegradable, non-toxic and harmless to humans and environments. ${ }^{1,2}$ Its raw materials mainly include oil crops, plants, ${ }^{3}$ animal fats ${ }^{4}$ and catering waste oil, ${ }^{5}$ which are low cost and readily available. Biodiesel is of high calorific value, has a stable combustion performance and can be used in compression-ignition engines. Thus it is a very promising alternative to conventional diesel.

There are many ways to produce biodiesel. Biodiesel produced by the direct blending method and the microemulsion method ${ }^{6,7}$ doesn't meet the diesel standards. While biodiesel prepared by the esterification and transesterification method $^{8}$ has very similar properties to petrochemical diesel, so it can be directly used in diesel engines. Now, homogeneous catalytic transesterification becomes a major industry production process for biodiesel production by using trifluoroacetic acid, sulfuric acid, sodium hydroxide, or potassium hydroxide. ${ }^{9}$ However, homogeneous catalytic transesterification ${ }^{10}$ has several disadvantages. For example, the catalyst is difficult to reuse, and a large amount of wastewater could be generated in the homogeneous catalytic process. In contrast, heterogeneous catalytic transesterification copes with most of the shortcomings of homogeneous process,

Key Laboratory of Applied Surface and Colloid Chemistry, School of Chemistry \& Chemical Engineering, Shaanxi Normal University, Xi'an, 710119, China. E-mail: rrhu@snnu.edu.cn

$\dagger$ Electronic supplementary information (ESI) available. See DOI: $10.1039 / \mathrm{c} 8 \mathrm{ra} 06884 \mathrm{~d}$ reactions. Yee ${ }^{11}$ prepared $\mathrm{Al}_{2} \mathrm{O}_{3} / \mathrm{Zr}\left(\mathrm{SO}_{4}\right)_{2}$ catalyst for biodiesel production and the yield of biodiesel reached $90.32 \%$. $\mathrm{Ma}^{12}$ synthesized $\mathrm{KOH} / \gamma-\mathrm{Al}_{2} \mathrm{O}_{3}$ catalyst and applied it to the transesterification of rapeseed oil. The yield of biodiesel reached $84.52 \%$ at $60^{\circ} \mathrm{C}$ for $1 \mathrm{~h}$ with a methanol to oil molar ratio of $9: 1$. Bimetallic Au@Ag nanoparticles showed high catalytic activities for the transesterification reaction and the highest yield of biodiesel from sunflower oil was about $86.9 \% .^{13}$ Magnetic materials, ${ }^{14}$ metallic monolithic catalysts ${ }^{15}$ and nanocatalysts such as $\mathrm{TiO}_{2}$ (ref. 16) and $\mathrm{ZnO}^{17}$ had also shown potential applications in biodiesel production.

In general, heterogeneous solid base catalysts have better catalytic activity than solid acid catalysts ${ }^{18}$ for feedstock oils with a low acid value, which is of higher catalytic efficiency and lower cost. ${ }^{19,20}$ Nowadays, a large number of different heterogeneous basic catalysts ${ }^{21}$ such as hydrotalcite, layeredstructured minerals, zeolites and alkaline earth metal oxides have been tested for biodiesel production. It has been reported that alkaline earth metal oxides were capable of producing higher biodiesel yield because of its higher basicity and the number of highly basic sites at the edges of the metal oxide cluster is one of the key factors to affect catalytic performance in the transesterification reaction..$^{22}$ Among them, $\mathrm{CaO}$, as a promising catalyst, has drawn much attention in transesterification reactions for biodiesel production. $\mathrm{CaO}$ shows high catalytic activity and does not have any major negative impact on the environment. ${ }^{23}$ It also has great economic advantages because of its low price and the convenience to be obtained from natural and waste materials. However, $\mathrm{CaO}$ is sensitive to the free fatty acids (FFAs). During the transesterification reactions, the leached calcium species will react 
with FFAs and result in soap formation. The deactivation problem caused by leaching of $\mathrm{Ca}^{2+}$ has been a main drawback of $\mathrm{CaO}$ catalyst. ${ }^{22}$ In order to improve the stability of calcium, numerous researchers have attempted to modify $\mathrm{CaO}$ with the second metal oxide, use Perovskites containing $\mathrm{Ca}$, or support $\mathrm{CaO}$ onto carriers. Significant enhancement on the reusability has been achieved over these CaO-based catalysts in the transesterification reaction due to the high surface area, strong basicity, and reduced sensitivity to FFAs. ${ }^{24}$ So far, $\mathrm{CaO}-\mathrm{CeO}_{2}$ catalyst has also been studied and it showed great potential compared with other CaO-based catalysts in the transesterification reaction. Wong ${ }^{25}$ prepared the $\mathrm{CaO}-\mathrm{CeO}_{2}$ catalysts via a impregnation method and the highest biodiesel yield reached $95 \%$. $\mathrm{Yu}^{26}$ reported the production of biodiesel over the $\mathrm{CaO}-\mathrm{CeO}_{2}$ catalysts by transesterification of Pistacia chinensis oil with methanol. The optimum yield of $91 \%$ was achieved at $110{ }^{\circ} \mathrm{C}$ for $6 \mathrm{~h}$ with a methanol to oil molar ratio of $30: 1$. $\mathrm{Yan}^{27}$ synthesized the $\mathrm{CaO}-\mathrm{CeO}_{2} / \mathrm{HAP}$ catalysts which presented excellent performance and stability due to the low leaching of catalyst components in the product phase. Reyero ${ }^{15}$ used CaO$\mathrm{CeO}_{2}$ supported metallic monolithic catalysts for the production of biodiesel and the highest conversion of sunflower oil was about $99 \%$, though significant leaching of the active catalytic layer was found during the second reaction cycle. Ceria itself was found inactive in the transesterification reaction, ${ }^{22,28}$ however, the synergy between calcium oxide and cerium oxide could reduce the leaching of $\mathrm{CaO}$ in biodiesel products when calcium oxide was incorporated into the cerium oxide.

In this study, a kind of novel core-shell $\mathrm{CeO}_{2} @ \mathrm{CaO}$ catalyst was prepared and tested in the transesterification of soybean oil with methanol under mild reaction conditions. The physicochemical properties of the prepared $\mathrm{CeO}_{2} @ \mathrm{CaO}$ catalysts were characterized by using several analytic techniques. Effects of the surface area, basicity, $\mathrm{CaO}$ loadings and morphology of the core-shell materials on biodiesel yield were studied. Catalyst stability and recycling performance in transesterification reaction were also investigated and the possibility of its reuse in repeated batch reactions was estimated.

\section{Experimental}

\section{Materials}

Calcium nitrate $\left(\mathrm{Ca}\left(\mathrm{NO}_{3}\right)_{2} \cdot 4 \mathrm{H}_{2} \mathrm{O}\right)$, cerium chloride heptahydrate $\left(\mathrm{CeCl}_{3} \cdot 7 \mathrm{H}_{2} \mathrm{O}\right)$, urea $\left(\mathrm{CO}\left(\mathrm{NH}_{2}\right)_{2}\right)$, methanol $\left(\mathrm{CH}_{3} \mathrm{OH}\right)$, hexadecyl trimethyl ammonium bromide (CTAB), calcium oxide $(\mathrm{CaO})$ and cerium oxide $\left(\mathrm{CeO}_{2}\right)$ were purchased from Sinopharm Chemical Reagent Factory, of analytical reagent grade. Non-transgenic soybean oil (Jiusan Cereals \& Oils Industry Group Co., Ltd.) was purchased from the local market.

\section{Catalysts preparation}

The core-shell $\mathrm{CeO}_{2} @ \mathrm{CaO}$ catalysts with composition 20$60 \mathrm{wt} \% \mathrm{CaO}$ were prepared by a hydrothermal method. To prepare the core-shell $\mathrm{CeO}_{2} @ \mathrm{CaO}$ sample with a $\mathrm{CaO}$ content of $20 \mathrm{wt} \%, 0.21 \mathrm{~g}$ of $\mathrm{CaO}$ and $0.1 \mathrm{~g}$ CTAB were added to $60 \mathrm{~mL}$ deionized water and dispersed under ultrasonication for
$10 \mathrm{~min}$. Then $0.86 \mathrm{~g} \mathrm{CeCl}_{3} \cdot 7 \mathrm{H}_{2} \mathrm{O}$ and $3 \mathrm{~g} \mathrm{CO}\left(\mathrm{NH}_{2}\right)_{2}$ were added and dissolved in the suspension completely followed by stirring for $0.5 \mathrm{~h}$ at room temperature. The mixture was then transferred to $100 \mathrm{~mL}$ Teflon-lined stainless steel autoclave and heated in an oven at $90{ }^{\circ} \mathrm{C}$ for $24 \mathrm{~h}$. After that, the products were separated by centrifugation and washed with anhydrous ethanol. Followed by a dry process at $100{ }^{\circ} \mathrm{C}$ for $3 \mathrm{~h}$ and then calcined at $750{ }^{\circ} \mathrm{C}$ for $6 \mathrm{~h}$ in air, the core-shell $\mathrm{CeO}_{2} @ \mathrm{CaO}$ sample with a $\mathrm{CaO}$ content of $20 \mathrm{wt} \%\left(\mathrm{CeO}_{2} @ \mathrm{CaO}-20\right)$ was obtained. The other core-shell $\mathrm{CeO}_{2} @ \mathrm{CaO}$ catalysts having $40 \mathrm{wt} \%$ and $60 \mathrm{wt} \% \mathrm{CaO}$ contents could be prepared following this procedure and they were labeled as $\mathrm{CeO}_{2} @ \mathrm{CaO}-x$, where $x$ represented the amount of $\mathrm{CaO}$ loaded on the catalyst.

The $\mathrm{CeO}_{2}-\mathrm{CaO}$ catalysts with composition $20-60 \mathrm{wt} \% \mathrm{CaO}$ were prepared via wet impregnation method and labeled as $\mathrm{CeO}_{2}-\mathrm{CaO}-x$, where $x$ represented the amount of $\mathrm{CaO}$ loaded on the catalyst. Briefly, $1 \mathrm{~g}$ of $\mathrm{Ca}\left(\mathrm{NO}_{3}\right)_{2} \cdot 4 \mathrm{H}_{2} \mathrm{O}$ was dissolved in $20 \mathrm{~mL}$ deionized water and a complementary amount of $\mathrm{CeO}_{2}$ was added slowly into this solution followed by heated at $90{ }^{\circ} \mathrm{C}$ until the water in solution completely evaporated. Then the resulting powder was dried in an oven at $100{ }^{\circ} \mathrm{C}$ for $3 \mathrm{~h}$ and calcined in a muffle furnace at $750^{\circ} \mathrm{C}$ for $6 \mathrm{~h}$. Finally, the $\mathrm{CeO}_{2}-$ CaO- $x$ catalyst was obtained.

\section{Catalysts characterization}

X-ray powder diffraction (XRD) was carried out on a Bruker D8 ADVANCE diffractometer fitted with $\mathrm{Cu}-\mathrm{K}$ radiation to determine the phase identity of the synthesized samples. The specific surface area of each sample was measured by using a Micromeritics ASAP 2460 Surface Area and Porosity Analyzer with the BET method. Transmission electron microscopy (TEM) images were examined by using a JEOL model JEM 2010 EX instrument. Energy dispersive X-ray analysis (EDAX) was recorded on a FEI Tecnai G2F20 instrument and operated at an accelerating voltage of $200 \mathrm{kV}$. Surface electronic states were analyzed using X-ray photoelectron spectroscopy (XPS) with an AXIS ULTRA spectrometer. The amount of catalyst elements was determined using the inductively coupled plasma optical emission spectrometer (ICP-OES), Perkin-Elmer Optima 3000V. Furthermore, the basic properties of samples were determined using temperature-programmed desorption with $\mathrm{CO}_{2}$ as a probe molecule, which were performed on a Micromeritics AutoChem 2920 II instrument with the temperature-programmed mode. The amount of $\mathrm{CO}_{2}$ desorbed in the temperature range of 100$900{ }^{\circ} \mathrm{C}$ was detected by thermal conductivity detector.

\section{Transesterification reaction}

The transesterification reaction of soybean oil and methanol was carried out in a three necked glass reactor with a reflux condenser and a magnetic stirrer. Typically, the calcined catalyst (3 wt\% calculated with respect to soybean oil) and the soybean oil were added in $30 \mathrm{~mL}$ methanol under stirring with a constant speed for the transesterification reactions. The methanol to soybean oil molar ratio was varied from $1: 1$ to $14: 1$. The mixture was refluxed at $60-80{ }^{\circ} \mathrm{C}$ in an oil bath with constant magnetic stirring 1-6 $\mathrm{h}$. After the reaction finished, the 
catalysts were then separated by centrifuging at $3000 \mathrm{rpm}$ for $30 \mathrm{~min}$. The obtained liquid products were placed in a funnel for phase separation. Biodiesel floated on the top layer while glycerol at the bottom. The desirable biodiesel obtained was further purified by distillation to remove the excess methanol.

The composition of the product obtained was analyzed by Gas Chromatography-Mass Spectrometry (GC-MS: 6890 N GC/ 5973 MS, Agilent Technologies). Since the main component of biodiesel is fatty acid methyl ester (FAME), the FAME yield also could be determined by ${ }^{1} \mathrm{H}$ nuclear magnetic resonance $\left({ }^{1} \mathrm{H}\right.$ NMR). ${ }^{29}{ }^{1} \mathrm{H}$ NMR spectra of the purified biodiesel production were recorded at ambient temperature on a Varian VXR-400 $\mathrm{MHz}$ spectrometer using standard procedures. The chemical shifts were referenced to the residual peaks of $\mathrm{CHCl}_{3}$ in $\mathrm{CDCl}_{3}$ (7.26 ppm). The percent yield of FAME was calculated by the ratio of the area of the single peak associated with methyl esters at $3.53 \mathrm{ppm}$ and the peak at $2.20 \mathrm{ppm}$ representative of the $\alpha$ methylene protons in the ester molecule. ${ }^{29,30}$

\section{Results and discussion}

\section{Catalysts characterization}

The power XRD patterns for various compositions $\mathrm{CeO}_{2} @ \mathrm{CaO}$ catalysts are shown in Fig. 1. For all of the samples, the diffraction peaks were clear and showed similar patterns. The peaks at $28.68^{\circ}, 33.30^{\circ}, 47.85^{\circ}, 56.35^{\circ}$ and $59.8^{\circ}$ were ascribed to the $(111)$, (200), (220), (311) and (222) planes of pure $\mathrm{CeO}_{2}$ with the fluoritetype cubic structure. The pure $\mathrm{CaO}$ gave well-defined diffraction peaks at $2 \theta$ values of $32.45,37.64,53.88,64.41$ and 67.68 . The $\mathrm{XRD}$ analysis of these $\mathrm{CeO}_{2}$ @CaO catalysts revealed they had the separate $\mathrm{CaO}$ and $\mathrm{CeO}_{2}$ crystalline phases and no new species or a binary phase such as $\mathrm{CaCeO}_{3}$ was found over these samples. From Fig. 1, the increase in $\mathrm{CaO}$ content resulted in an increase and a slight decrease in the peak intensities of $\mathrm{CaO}$ and $\mathrm{CeO}_{2}$, respectively. This may be attributed to the coating of $\mathrm{Ca}^{2+}$ species on the surface of ceria and their higher X-ray scattering factor of $\mathrm{Ca}^{2+}$ compared to the $\mathrm{Ce}^{4+}$ ions. ${ }^{28}$

The surface areas, pore volumes and average pore diameters of the $\mathrm{CeO}_{2} @ \mathrm{CaO}$ catalysts are listed in Table 1. As the $\mathrm{CaO}$

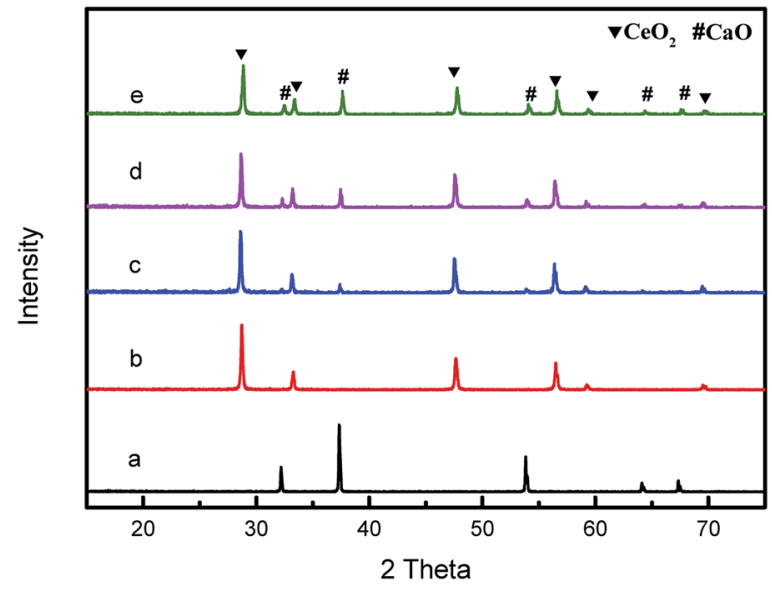

Fig. 1 XRD patterns of the $\mathrm{CeO}_{2}\left(\mathrm{aCaO}\right.$ catalysts (a): $\mathrm{CaO},(\mathrm{b}): \mathrm{CeO}_{2}$, (c): $\mathrm{CeO}_{2}\left(\mathrm{aCaO}-20,(d): \mathrm{CeO}_{2}\left(\mathrm{aCaO}-40\right.\right.$, (e): $\mathrm{CeO}_{2} @ \mathrm{CaO}-60$.
Table 1 Surface area, pore volume and average pore diameter of the $\mathrm{CeO}_{2} \mathrm{aCaO}$ catalysts

\begin{tabular}{llll}
\hline Samples & $\begin{array}{l}\text { Surface area } \\
\mathrm{m}^{2} \mathrm{~g}^{-1}\end{array}$ & $\begin{array}{l}\text { Pore volume } \\
\mathrm{cm}^{3} \mathrm{~g}^{-1}\end{array}$ & $\begin{array}{l}\text { Average pore } \\
\text { diameter } \mathrm{nm}\end{array}$ \\
\hline $\mathrm{CeO}_{2} @ \mathrm{CaO}-20$ & 8.75 & 0.0640 & 19.26 \\
$\mathrm{CeO}_{2} @ \mathrm{CaO}-40$ & 13.56 & 0.0809 & 27.37 \\
$\mathrm{CeO}_{2} @ \mathrm{CaO}-60$ & 16.44 & 0.1038 & 26.30 \\
$\mathrm{CaO}$ & 11.65 & 0.1155 & 20.90 \\
\hline
\end{tabular}

content in catalysts increased from $20 \mathrm{wt} \%$ to $60 \mathrm{wt} \%$, the surface areas and pore volumes of the samples increased significantly from $8.75 \mathrm{~m}^{2} \mathrm{~g}^{-1}$ to $16.44 \mathrm{~m}^{2} \mathrm{~g}^{-1}$ and $0.064 \mathrm{~cm}^{3} \mathrm{~g}^{-1}$ to $0.103 \mathrm{~cm}^{3}$ $\mathrm{g}^{-1}$, respectively. While further increasing calcium loading from $60 \mathrm{wt} \%$ to $100 \mathrm{wt} \%$, the surface area of the catalysts decreased from $16.44 \mathrm{~m}^{2} \mathrm{~g}^{-1}$ to $11.65 \mathrm{~m}^{2} \mathrm{~g}^{-1}$. From Table 1 , the pore diameters of all samples were in the range of $10-50 \mathrm{~nm}$, which is beneficial for the reaction of large reactants because the limitation of pore diffusion in the transesterification reaction can be reduced using mesopore catalysts. ${ }^{31}$

The basic property of the catalysts was evaluated using temperature programmed desorption of $\mathrm{CO}_{2} \cdot \mathrm{CO}_{2}$-TPD profile over the core-shell $\mathrm{CeO}_{2} @ \mathrm{CaO}$ catalysts is shown in Fig. 2. It revealed that some of the $\mathrm{CeO}_{2} @ \mathrm{CaO}$ catalysts contained two desorption peaks. The desorption peaks around $200{ }^{\circ} \mathrm{C}$ can be assigned to the interaction between $\mathrm{CO}_{2}$ and weak basic sites. The desorption peaks around $570-640{ }^{\circ} \mathrm{C}$ can be assigned to existence of strong basic sites. The strong basic sites of $\mathrm{CeO}_{2} @ \mathrm{CaO}$ catalysts showed the existence of oxygen in $\mathrm{Ca}-\mathrm{O}$, $\mathrm{Ce}-\mathrm{O}_{2}$ ion pairs and isolated $\mathrm{O}_{2}{ }^{-}$anions, which was helpful to initiate the transesterification reaction. ${ }^{32}$ From Fig. 2, the basicity of the $\mathrm{CeO}_{2} @ \mathrm{CaO}-60$ catalyst was found to be higher than both bulk $\mathrm{CaO}$ and $\mathrm{CeO}_{2}$. The improved basicity of the sample was due to the synergetic effect between $\mathrm{CaO}$ and $\mathrm{CeO}_{2}$. Furthermore, it was found that the $\mathrm{CeO}_{2}$ @CaO-60 sample had the highest $\mathrm{CO}_{2}$ desorption temperature and largest number of basic sites, which also had been proved it had the highest catalytic activity in the transesterification reaction.

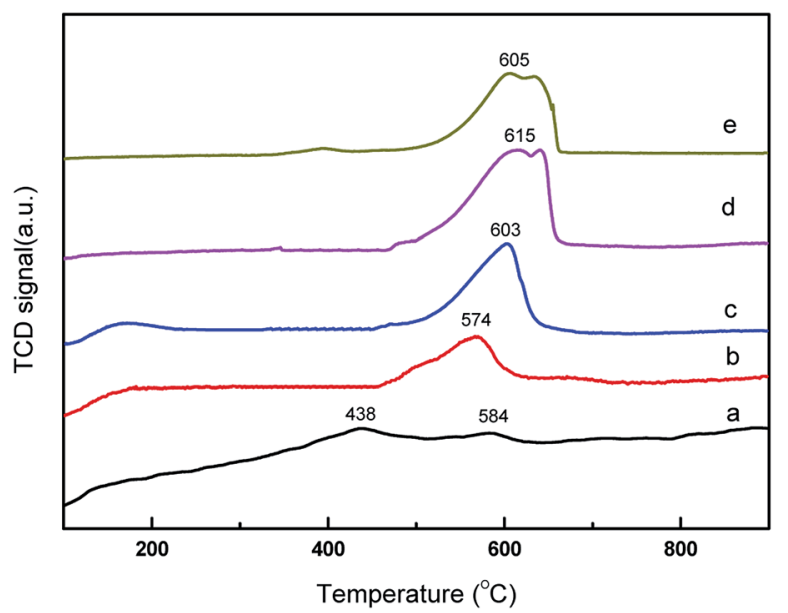

Fig. $2 \mathrm{CO}_{2}$-TPD analysis of the $\mathrm{CeO}_{2} \mathrm{aCaO}$ catalysts (a): $\mathrm{CeO}_{2},(\mathrm{~b})$ : $\mathrm{CeO}_{2} \mathrm{aCaO}-20$, (c): $\mathrm{CeO}_{2}\left(\mathrm{CaO}-40\right.$, (d): $\mathrm{CeO}_{2} \mathrm{aCaO}-60$, (e): $\mathrm{CaO}$ 
Fig. 3 shows the transmission electron microscope (TEM) images of the $\mathrm{CeO}_{2} @ \mathrm{CaO}$ and $\mathrm{CeO}_{2}-\mathrm{CaO}$ catalysts. It was noted that the morphology of $\mathrm{CeO}_{2} @ \mathrm{CaO}$ samples was very different from that of $\mathrm{CeO}_{2}-\mathrm{CaO}$. The existence of the dark areas (inner layer, core) and bright areas (outer layer, shell) in TEM images clearly shows the core-shell structure of $\mathrm{CeO}_{2} @ \mathrm{CaO}$ nanocomposite with a particle size of 400-600 nm, in which the core is spatially and compactly encaged within a shell. The diameter of the core and shell was 100-300 nm and 200-400 nm, respectively. The particle size of $\mathrm{CeO}_{2}-\mathrm{CaO}$ catalysts was much smaller than that of $\mathrm{CeO}_{2} @ \mathrm{CaO}$ and it was in the range of 15-40 $\mathrm{nm}$ for all the $\mathrm{CeO}_{2}-\mathrm{CaO}$ catalysts. In addition, it can be seen that with the increase of Ca contents, the particle size of the catalysts increased. The results indicated that the $\mathrm{Ca}$ content had a significant effect on the particle size of the catalysts.

Fig. 4 shows the EDS mapping of the $\mathrm{CeO}_{2} @ \mathrm{CaO}-60$ catalysts. It demonstrated just only $\mathrm{Ce}, \mathrm{Ca}$, and $\mathrm{O}$ elements existed in the core-shell samples and it was $\mathrm{CaO}$ that covers the core of $\mathrm{CeO}_{2}$ completely. The elemental compositions of the $\mathrm{CeO}_{2}$ @CaO-60 catalyst also could be estimated by using Energy dispersive X-ray analysis (EDXA) and the results are listed in Table 2. For the $\mathrm{CeO}_{2}$ @CaO-60 catalyst, the $\mathrm{CaO}$ content of that is $60 \mathrm{wt} \%$ and the theoretical $\mathrm{Ca} / \mathrm{Ce}$ atomic ratio is about 4.61 by calculation. From Table 2, the measured $\mathrm{Ca} / \mathrm{Ce}$ atomic ratio is 4.01, which means the predicted and experimental compositions were in good agreement with each other with no significant deviation observed.

Fig. 5 and 6 present the XPS spectra of $\mathrm{Ca} 2 \mathrm{p}$, Ce $3 \mathrm{~d}$ and $\mathrm{O} 1 \mathrm{~s}$ for $\mathrm{CeO}_{2} @ \mathrm{CaO}$ samples, respectively. It can be observed that $\mathrm{Ca}$ 2p spectra (Fig. 5) displayed two main characteristic peaks with $\mathrm{BE}$ around at $347 \mathrm{eV}$ and $351 \mathrm{eV}$. With the increase of Ce content, the BE of Ca $2 p$ shifted slightly from $347.2 \mathrm{eV}$ toward
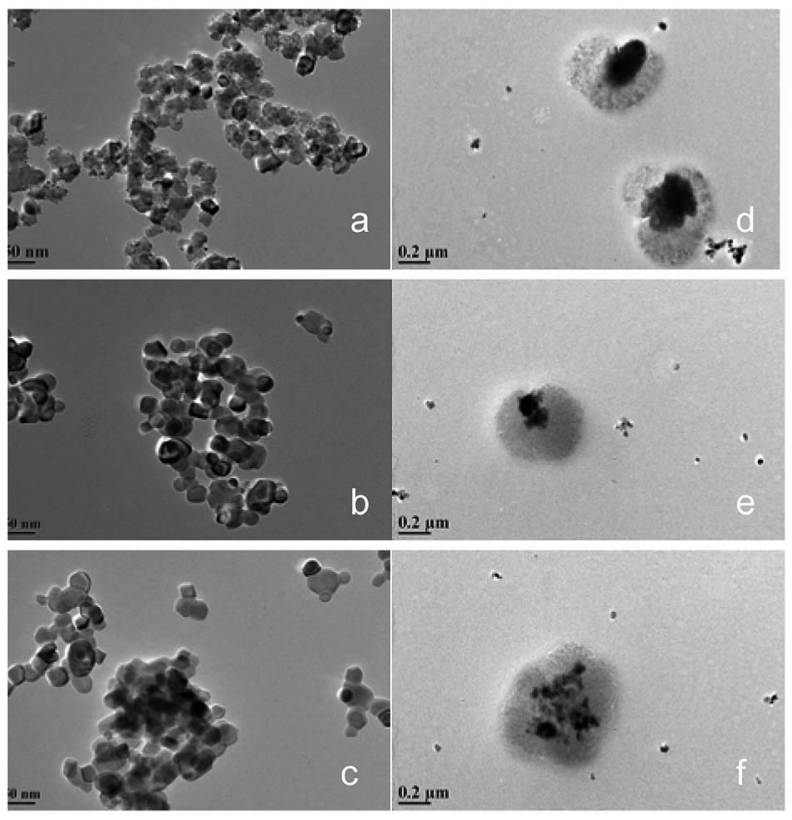

Fig. 3 TEM images of the $\mathrm{CeO}_{2} \mathrm{aCaO}$ and $\mathrm{CeO}_{2}-\mathrm{CaO}$ catalysts (a): $\mathrm{CeO}_{2}-\mathrm{CaO}-20$, (b): $\mathrm{CeO}_{2}-\mathrm{CaO}-40$, (c): $\mathrm{CeO}_{2}-\mathrm{CaO}-60$, (d): $\mathrm{CeO}_{2} \mathrm{aCaO}-20$, (e): $\mathrm{CeO}_{2} \mathrm{aCaO}-40$, (f): $\mathrm{CeO}_{2} \mathrm{aCaO}-60$.
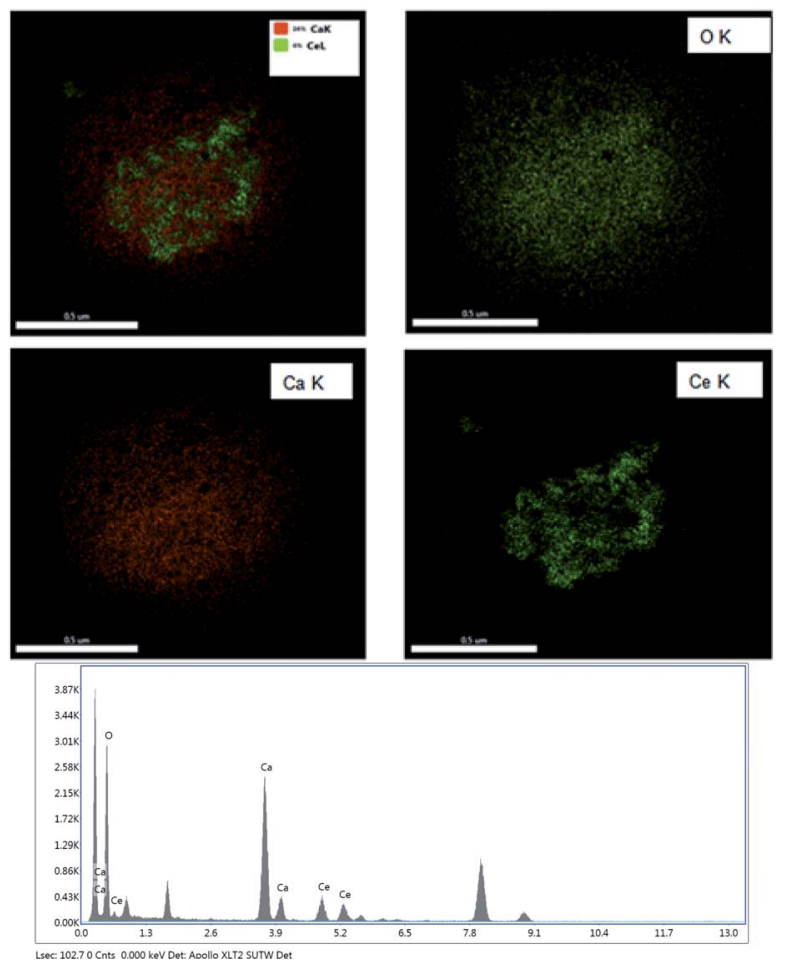

Fig. 4 The EDS mapping and EDX analysis of the $\mathrm{CeO}_{2} \mathrm{aCaO}-60$ catalyst.

Table 2 The content of elements obtained from EDX analysis for the $\mathrm{CeO}_{2} @ \mathrm{aCaO}-60$ catalyst

\begin{tabular}{llc}
\hline Element & Weight(\%) & Atomic(\%) \\
\hline O K & 24.32 & 54.46 \\
Ca K & 40.85 & 36.61 \\
Ce L & 34.83 & 8.93 \\
\end{tabular}

a lower value $346.6 \mathrm{eV}$, suggesting the interaction of Ce with the catalyst surface.

The Ce $3 \mathrm{~d}$ level has a very complicated structure and the Ce 3d spectra can be deconvoluted into eight peaks: $\mathrm{v}(\sim 883.8 \mathrm{eV})$, $\mathrm{v}^{\prime}(\sim 885.6 \mathrm{eV}), \mathrm{v}^{\prime \prime}(\sim 888.2 \mathrm{eV}), \mathrm{v}^{\prime \prime \prime}(\sim 898.1 \mathrm{eV}), \mathrm{u}(\sim 901.7 \mathrm{eV}), \mathrm{u}^{\prime}$ ( $\sim 906.0 \mathrm{eV}), \mathrm{u}^{\prime \prime}(\sim 908.2 \mathrm{eV})$ and $\mathrm{u}^{\prime \prime \prime}(\sim 916.0 \mathrm{eV})$. The four $\mathrm{U}$ bands represent $\mathrm{Ce} 3 \mathrm{~d}_{3 / 2}$, and the four $\mathrm{V}$ bands represent $\mathrm{Ce}$ $3 \mathrm{~d}_{5 / 2}$. Six peaks corresponding to three pairs of spin-orbit doublets $\left[(\mathrm{V}, \mathrm{U}),\left(\mathrm{V}^{\prime \prime}, \mathrm{U}^{\prime \prime}\right)\right.$, and $\left.\left(\mathrm{V}^{\prime \prime \prime}, \mathrm{U}^{\prime \prime \prime}\right)\right]$ can be identified with the $3 \mathrm{~d}^{10} 4 \mathrm{f}^{0}$ state of the $\mathrm{Ce}^{4+}$ species, while two peaks due to one pair of doublets $\left(V^{\prime}, U^{\prime}\right)$ characterize the $3 \mathrm{~d}^{10} 4 \mathrm{f}^{1}$ state of the $\mathrm{Ce}^{3+}$ species. ${ }^{33}$ As shown in Fig. 6a and Table 3, when the Ca content increased, the $\mathrm{BE}$ of $\mathrm{Ce}^{3+}$ and $\mathrm{Ce}^{4+}$ slightly shifted to a higher value, suggesting that the electron transfer from lattice oxygen atoms to metal atoms. ${ }^{22}$ In addition, the surface atomic ratio of $\mathrm{Ce}^{3+}: \mathrm{Ce}^{4+}$, which was calculated by all the peaks, decreased with the Ca content, indicating a strong interaction between $\mathrm{Ca}$ and $\mathrm{Ce}^{34}$

The $\mathrm{O}$ 1s spectra of these samples (Fig. 6b) showed three states of surface oxygen: the lattice oxygen $\mathrm{O}_{\mathrm{I}}(\sim 529.0 \mathrm{eV})$, the adsorbed oxygen $\mathrm{O}_{\text {II }}(\sim 531.0 \mathrm{eV})$ and the adsorbed carbonates 


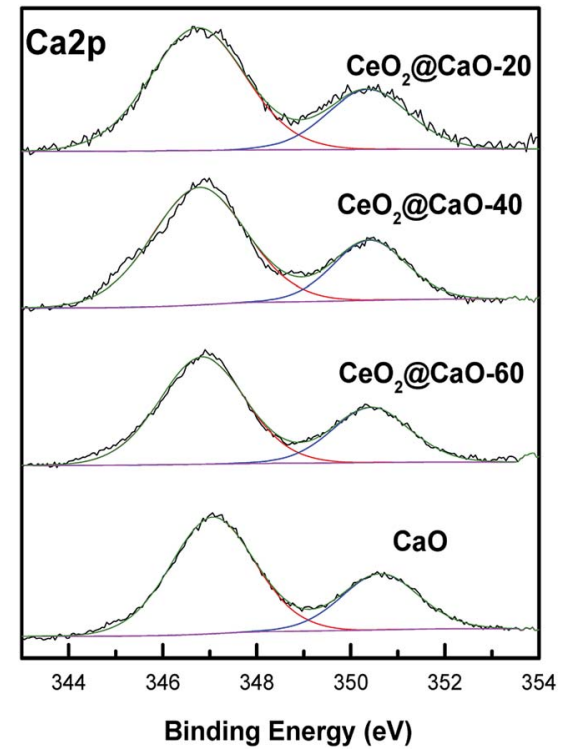

Fig. $5 \mathrm{Ca} 2 \mathrm{p}$ XPS spectra of the $\mathrm{CeO}_{2} \mathrm{aCaO}$ catalysts.

and/or water $\mathrm{O}_{\text {III }}(\sim 533.5 \mathrm{eV}) .{ }^{35}$ The ratio of $\mathrm{O}_{\text {I }}$ to $\mathrm{O}_{\text {III }}$ for all samples was calculated in Table 3 (See ESI $\dagger$ for the details about the XPS results of $\mathrm{O} 1 \mathrm{~s}$ for the $\mathrm{CeO}_{2} @ \mathrm{CaO}$ samples). From it, the $\mathrm{O}_{\mathrm{I}}$ to $\mathrm{O}_{\mathrm{II}}$ ratios of the $\mathrm{CeO}_{2} @ \mathrm{CaO}$ catalysts are remarkably higher than that of the $\mathrm{CaO}$ catalyst, indicating that the incorporation of cerium can increase the amount of lattice oxygen on the surface of the $\mathrm{CeO}_{2} @ \mathrm{CaO}$ catalysts due to the synergistic effect between $\mathrm{CaO}$ and $\mathrm{CeO}_{2} \cdot{ }^{33}$ The $\mathrm{O}^{2-}$ species has been reported to be the strong base site for solid base catalysts. ${ }^{36,37}$ For the $\mathrm{CeO}_{2} @ \mathrm{CaO}-60$ catalyst, the $\mathrm{O}_{\mathrm{I}}$ to $\mathrm{O}_{\mathrm{II}}$ ratios is 0.86 , which is highest among all the CaO-based catalysts, so it has the strongest basic strength. It is particularly noted that the $\mathrm{CeO}_{2}$ had very low basicity due to the nature of the oxygen species of $\mathrm{CeO}_{2}$ (ref. 38), though it also has a high $\mathrm{O}_{\mathrm{I}}$ to $\mathrm{O}_{\mathrm{II}}$ ratio.

\section{Catalytic activity}

Catalytic activity of various $\mathrm{CeO}_{2} @ \mathrm{CaO}$ catalysts for the transesterification of soybean oil was carried out under conditions of $3 \mathrm{wt} \%$ catalysts, methanol to soybean oil molar ratio of $12: 1$ and reaction temperature of $70{ }^{\circ} \mathrm{C}$. Fig. 7 shows the effect of reaction time on FAME yield over all samples. From it, the cerium oxide catalyst showed very poor catalytic performance due to the low basicity and the FAME yield was less than $10 \%$ even after 6 h. For all the $\mathrm{CeO}_{2} @ \mathrm{CaO}$ and pure $\mathrm{CaO}$ catalysts, the transesterification reaction started rapidly and the FAME yield reached more than $80 \%$ in the first $2 \mathrm{~h}$. The maximum yield was $98 \%$ with a reaction time of $3 \mathrm{~h}$ over $\mathrm{CeO}_{2}$ @CaO-20 catalyst and after this time the FAME yield has been constant, indicating that the active sites of the catalyst were available for the transesterification reaction.

The effect of reaction temperature on the catalytic activity over the $\mathrm{CeO}_{2}$ @CaO-60 catalyst with a methanol to oil molar ratio of 12 , catalyst amount of $3 \%$ and reaction time of $6 \mathrm{~h}$ is shown in Fig. 8. From it, the FAME yield can reach more than $70 \%$ from $60{ }^{\circ} \mathrm{C}$ to $80{ }^{\circ} \mathrm{C}$ and the highest yield is $98 \%$ at $70{ }^{\circ} \mathrm{C}$. (a)

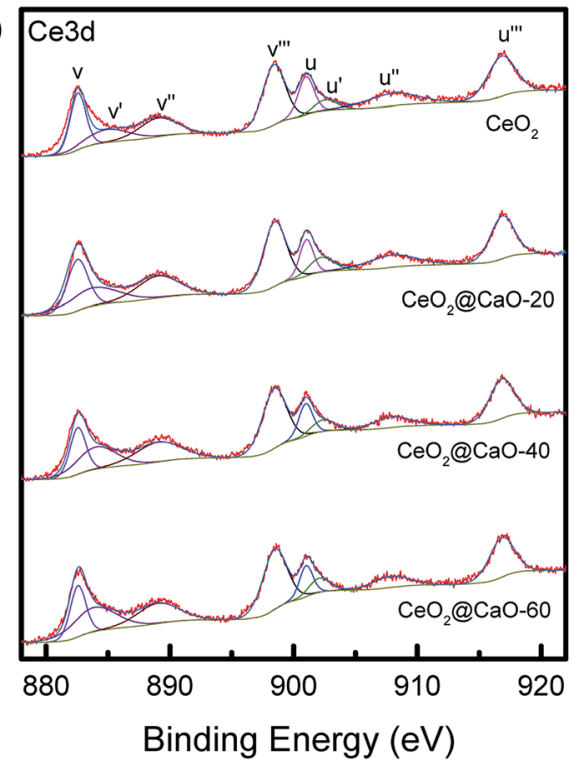

(b)

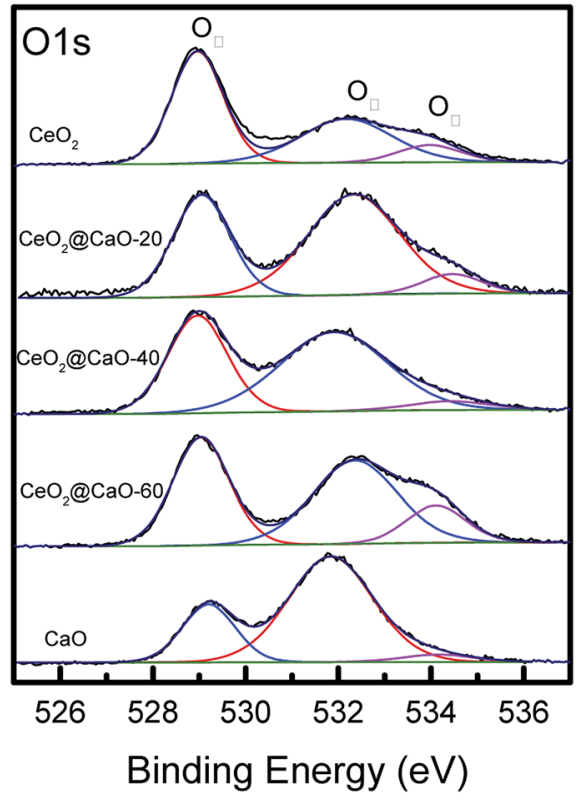

Fig. 6 Ce 3d XPS spectra (a) and O 1s XPS spectra (b) of the $\mathrm{CeO}_{2} \mathrm{OCaO}$ catalysts.

Table 3 XPS results of the $\mathrm{CeO}_{2} \mathrm{aCaO}$ catalysts

\begin{tabular}{|c|c|c|c|c|c|}
\hline \multirow[b]{2}{*}{ Catalyst } & \multirow[b]{2}{*}{$\mathrm{Ca} 2 \mathrm{p}_{3 / 2}$} & \multicolumn{2}{|c|}{ Ce $3 d_{5 / 2}$} & \multirow[b]{2}{*}{$\mathrm{Ce}^{3+}: \mathrm{Ce}^{4+}$} & \multirow[b]{2}{*}{$\mathrm{O}_{\mathrm{I}}: \mathrm{O}_{\mathrm{I}}$} \\
\hline & & $\left(\mathrm{Ce}^{4+}\right)$ & $\left(\mathrm{Ce}^{3+}\right)$ & & \\
\hline $\mathrm{CeO}_{2}$ & & 898.1 & 883.9 & 0.49 & 1.43 \\
\hline $\mathrm{CeO}_{2} @ \mathrm{CaO}-20$ & 346.6 & 898.1 & 884.0 & 0.45 & 0.62 \\
\hline $\mathrm{CeO}_{2} @ \mathrm{CaO}-40$ & 346.8 & 898.3 & 884.2 & 0.41 & 0.69 \\
\hline $\mathrm{CeO}_{2} @ \mathrm{CaO}-60$ & 347.0 & 898.4 & 884.8 & 0.34 & 0.86 \\
\hline $\mathrm{CaO}$ & 347.2 & & & & 0.35 \\
\hline
\end{tabular}

Below $70{ }^{\circ} \mathrm{C}$, the FAME yield increased with an increase in the reaction temperature and decreased when further increasing the temperature. The higher temperature is favourable for 


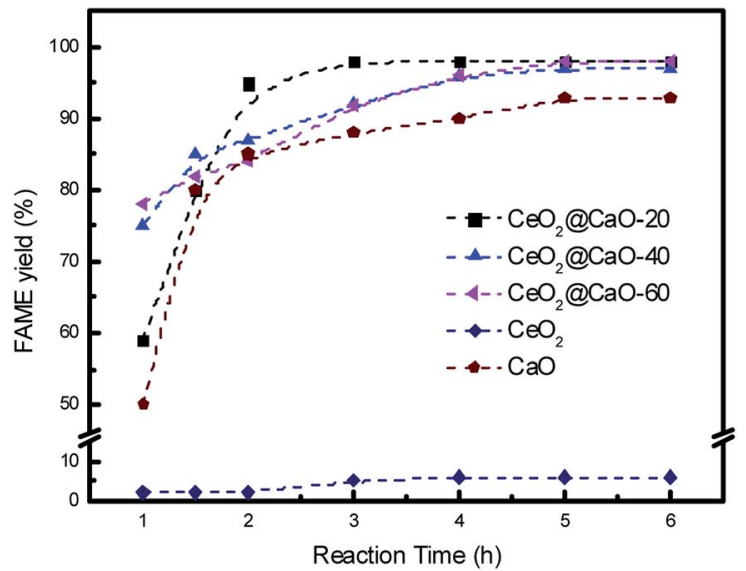

Fig. 7 Effect of reaction time on the FAME yield over the $\mathrm{CeO}_{2}(\mathrm{aCaO}$ catalysts.

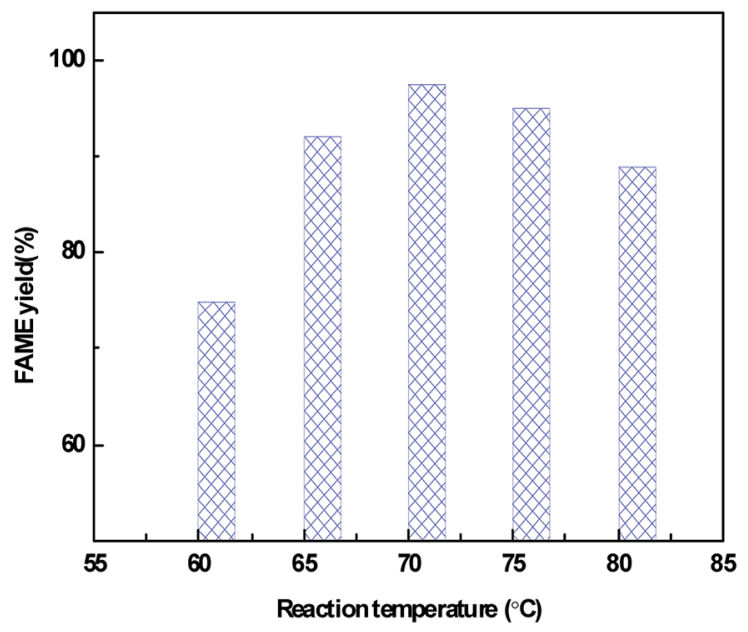

Fig. 8 Effect of reaction temperature on the FAME yield over the $\mathrm{CeO}_{2} @ \mathrm{CaO}-60$ catalyst.

biodiesel synthesis since the transesterification reaction is an endothermic reaction. However, when the reaction temperature was higher than $64.7^{\circ} \mathrm{C}$, a large amount of methanol evaporation rose with increasing temperature, resulting in a concentration decrease of methanol in the reaction. These two combined effects leaded to an optimum reaction temperature of $70{ }^{\circ} \mathrm{C}$ for the transesterification reaction.

Fig. 9 presents the effect of the methanol to oil molar ratio on the FAME yield at the best condition found in Fig. 8. Molar ratio of methanol to oil is one of the most significant factors affecting the FAME yield as well biodiesel production cost. Since the transesterification reaction is reversible, higher molar ratios are beneficial to increasing the oil conversion by shifting this equilibrium to the production of biodiesel. From Fig. 9, when methanol to oil molar ratio increased from $1: 1$ to $10: 1$, the FAME yield catalyzed by the $\mathrm{CeO}_{2} @ \mathrm{CaO}-60$ sample increased gradually and reached the maximum values of $98 \%$. However, the FAME yield was slightly reduced when the methanol to oil molar ratio was $14: 1$. The decrease in FAME yield might be due partly to the remaining of glycerol in the biodiesel phase since

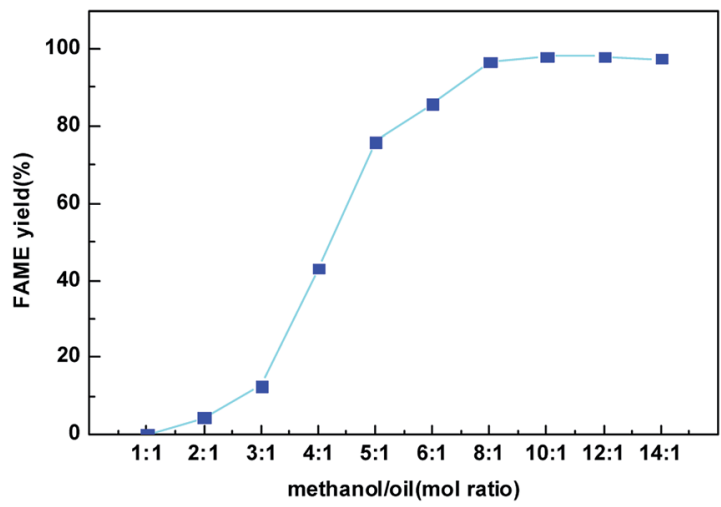

Fig. 9 Effect of methanol to oil mol ratio on the FAME yield over the $\mathrm{CeO}_{2} \mathrm{aCaO}-60$ catalyst.

methanol could act as an emulsifier ${ }^{27,28}$ and render glycerol separation complicated.

\section{Catalyst stability}

As mentioned earlier, one of the advantages of the heterogeneous catalytic transesterification over the homogeneous process is the easy separation and reuse of the solid catalyst.

Fig. 10 presents the stability study of the pure $\mathrm{CaO}$, $\mathrm{CeO}_{2} @ \mathrm{CaO}-60$ and $\mathrm{CeO}_{2}-\mathrm{CaO}-60$ catalyst for the transesterification of soybean oil at $70{ }^{\circ} \mathrm{C}$ for $6 \mathrm{~h}$ with a methanol to oil molar ratio of $12: 1$ and catalyst amount of $3 \mathrm{wt} \%$. After each reaction finished, the catalyst was separated, washed with a mixture solution of methanol and $n$-heptane for several times and then dried in oven for $6 \mathrm{~h}$ before used in the next cycle. From Fig. 10, the FAME yield decreased sharply over pure $\mathrm{CaO}$ and was less than $30 \%$ at the fourth cycle. The $\mathrm{CeO}_{2}-\mathrm{CaO}-60$ catalyst had better stability than $\mathrm{CaO}$ though the FAME yield eventually dropped 50\% after the sixth run. For the $\mathrm{CeO}_{2} @ \mathrm{CaO}-$ 60 catalyst, it could maintain more than 80\% FAME yield even after 9 cycles and has better performance than both pure $\mathrm{CaO}$ and the $\mathrm{CeO}_{2}-\mathrm{CaO}-60$ catalyst. In general, there are two possible factors that contribute to the deactivation of the $\mathrm{CaO}$ based catalysts. One is the leaching of $\mathrm{CaO}$ into product phase and the other is the surface poisoning such as the adsorption of fatty acid, glycerol or glycerides on the active sites.

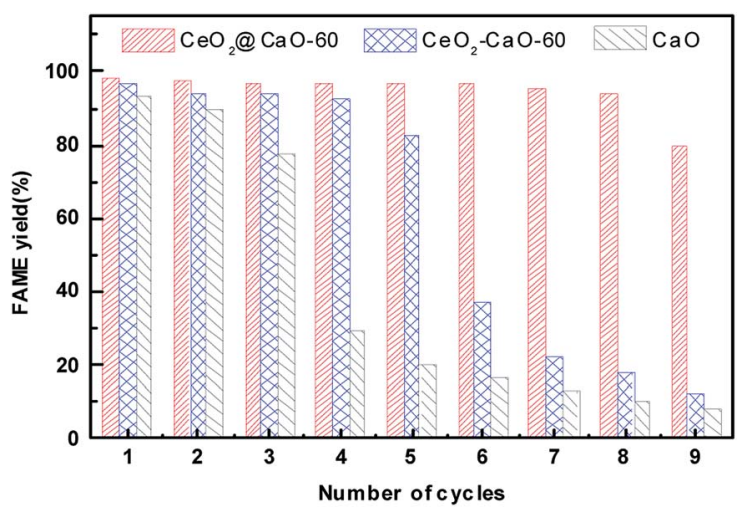

Fig. 10 The stability test of the $\mathrm{CaO}, \mathrm{CeO}_{2} \mathrm{aCaO}-60$ and $\mathrm{CeO}_{2}-\mathrm{CaO}-$ 60 catalysts. 


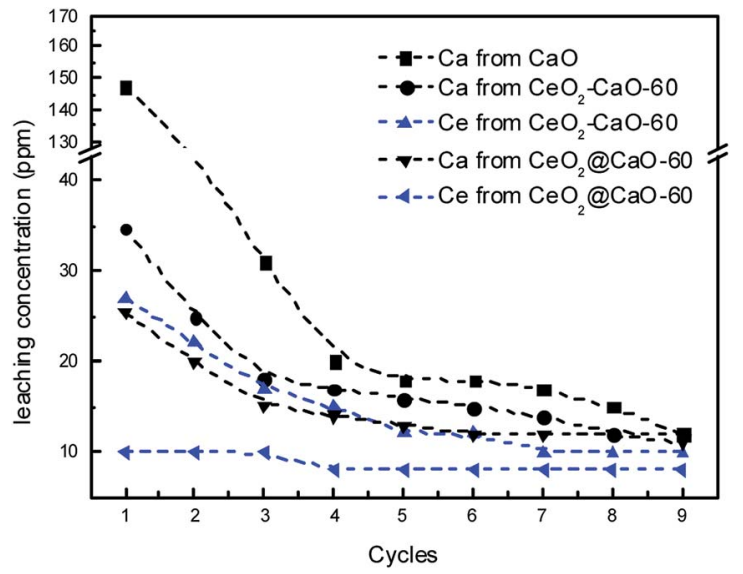

Fig. 11 The leaching concentrations of calcium and cerium species during the stability test.

In order to investigate the leaching of those used catalysts, the concentrations of $\mathrm{Ca}$ and Ce species were measured using ICP method after each cycle and presented in Fig. 11. The results revealed an obvious loss of calcium species in the biodiesel products over all the three catalysts. The pure $\mathrm{CaO}$ showed the highest concentration of calcium in the biodiesel layer with $147.4 \mathrm{ppm}$ detected. In contrast, the dissolved calcium species in the biodiesel phase catalyzed by the CeO ${ }_{2} @ \mathrm{CaO}-60$ and $\mathrm{CeO}_{2}-\mathrm{CaO}-60$ samples were about 25.3 and 34.7 ppm, respectively. The calcium concentration of those catalysts leached into the product phase decreased sharply at the first three cycles, becoming lower than 15 ppm after the 9th cycle. It is interesting to note that the leaching of Ce was more than 25 ppm over the $\mathrm{CeO}_{2}-\mathrm{CaO}-60$ catalyst. This implies that the deactivation of this catalyst is due to the leaching of Ce and $\mathrm{Ca}$. However, for the $\mathrm{CeO}_{2} @ \mathrm{CaO}-60$ catalyst, the loss of Ce in the biodiesel was in the range of 8-10 ppm, which was relatively small. This result indicated that special core-shell structure of the $\mathrm{CeO}_{2} @ \mathrm{CaO}$ catalyst could inhibit the leaching of $\mathrm{Ce}$ into the product phase when it was embedded in calcium oxide. $\mathrm{CeO}_{2}$, in turn, is able to stabilize the active phases and improve the stability of the catalyst.

\section{Conclusions}

The $\mathrm{CeO}_{2} @ \mathrm{CaO}$ catalysts, which have been successfully prepared via a hydrothermal method, showed better catalytic performance than pure $\mathrm{CaO}$ and the $\mathrm{CeO}_{2}-\mathrm{CaO}$ catalysts synthesized by a wet impregnation method for the production of biodiesel from soybean oil. The highest FAME yield can reach 98\% over the $\mathrm{CeO}_{2} @ \mathrm{CaO}-60$ catalysts under the optimum reaction conditions. In addition, the catalyst could be reused up to 9 times with good activity and get more than 80\% FAME yield. The excellent performance of the $\mathrm{CeO}_{2} @ \mathrm{CaO}$ catalysts for the transesterification reaction was possibly due to the strong synergic interaction between $\mathrm{CeO}_{2}$ and $\mathrm{CaO}$. This interaction was attributed to the special core-shell structure of these samples with $\mathrm{Ce}$ embedded in calcium oxide. $\mathrm{CeO}_{2}$ could stabilize the active phases, reduce the leaching of $\mathrm{Ca}$ into the product phase and improve the stability of the catalyst during the reactions. These results suggest that a core-shell $\mathrm{CeO}_{2}$ @$\mathrm{CaO}$ material is a promising catalyst for the green biodiesel production process.

\section{Conflicts of interest}

There are no conflicts to declare.

\section{Acknowledgements}

The work is supported by National Natural Science Foundation of China $(21276254,21636006)$ and the Fundamental Research Funds for the Central Universities (GK201603051, GK201601005).

\section{Notes and references}

1 R. Luque, J. C. Lovett, B. Datta, J. Clancy, J. M. Campelo and A. A. Romero, Energy Environ. Sci., 2010, 3, 1706-1721.

2 S. L. Falasca, N. Flores, M. C. Lamas, S. M. Carballo and A. Anschau, Int. J. Hydrogen Energy, 2010, 35, 5808-5812.

3 N. Dizge, C. Aydiner, D. Y. Imer, M. Bayramoglu, A. Tanriseven and B. Keskinlera, Bioresour. Technol., 2009, 100, 1983-1991.

4 V. Punsuvon, R. Nokkaew, P. Somkliang, M. Tapanwong and S. Karnasuta, Energy Sources, Part A, 2015, 37, 846-853.

5 T. A. Ngo, M. S. Kim and S. J. Sim, Int. J. Hydrogen Energy, 2011, 36, 5836-5842.

6 S. Jain and M. P. Sharma, Renewable Sustainable Energy Rev., 2010, 14, 763-771.

7 K. Tong, C. H. Zhao, Z. C. Sun and D. J. Sun, ACS Sustainable Chem. Eng., 2015, 3, 3299-3306.

8 G. J. Tao, Z. L. Hua, Z. Gao, Y. Chen, L. J. Wang, Q. J. He, H. R. Chen and J. L. Shi, RSC Adv., 2012, 2, 12337-12345.

9 X. L. Miao, R. X. Li and H. Y. Yao, Energy Convers. Manage., 2009, 50, 2680-2684.

10 C. H. Su, Appl. Energy, 2013, 104, 503-509.

11 K. F. Yee, K. T. Lee, R. Ceccato and A. Z. Abdullah, Bioresour. Technol., 2011, 102, 4285-4289.

12 H. B. Ma, S. F. Li, B. Y. Wang, R. H. Wang and S. J. Tian, J. Am. Oil Chem. Soc., 2008, 85, 263-270.

13 M. Banerjee, B. Dey, J. Talukdar and M. C. Kalita, Energy, 2014, 69, 695-699.

14 P. B. Zhang, M. Shi, Y. L. Liu, M. M. Fan, P. P. Jiang and Y. M. Dong, Fuel, 2016, 186, 787-791.

15 I. Reyero, A. Moral, F. Bimbela, J. Radosevic, O. Sanz, M. Montes and L. M. Gandia, Fuel, 2016, 182, 668-676.

16 D. Salinas, P. Araya and S. Guerrero, Appl. Catal., B, 2012, 117, 260-267.

17 Z. Q. Yang and W. L. Xie, Fuel Process. Technol., 2007, 88, 631-638.

18 K. L. Yang, S. Huang, H. Pan, H. Zhang, X. F. Liu and S. Yang, RSC Adv., 2017, 7, 33335-33343.

19 S. W. Gong, J. Lu, H. H. Wang, L. J. Liu and Q. Zhang, Appl. Energy, 2014, 134, 283-289. 
20 J. Y. Fu, L. G. Chen, P. M. Lv, L. M. Yang and Z. H. Yuan, Fuel, 2015, 154, 1-8.

21 O. Babajide, N. Musyoka, L. Petrik and F. Ameer, Catal. Today, 2012, 190, 54-60.

22 W. Thitsartarn and S. Kawi, Green Chem., 2011, 13, 34233430 .

23 D. M. Marinkovic, M. V. Stankovic, A. V. Velickovic, J. M. Avramovic, M. R. Miladinovic, O. O. Stamenkovic, V. B. Veljkovic and D. M. Jovanovic, Renewable Sustainable Energy Rev., 2016, 56, 1387-1408.

24 M. L. Granados, M. D. Z. Poves, D. M. Alonso, R. Mariscal, F. C. Galisteo, R. Moreno-Tost, J. Santamaria and J. L. G. Fierro, Appl. Catal., B, 2007, 73, 317-326.

25 Y. C. Wong, Y. P. Tan, Y. H. Taufiq-Yap, I. Ramli and H. S. Tee, Fuel, 2015, 162, 288-293.

26 X. H. Yu, Z. Wen, H. L. Li, S. T. Tu and J. Y. Yan, Fuel, 2011, 90, 1868-1874.

27 B. B. Yan, Y. Zhang, G. Y. Chen, R. Shan, W. C. Ma and C. Y. Liu, Energy Convers. Manage., 2016, 130, 156-164.

28 S. H. Teo, U. Rashid and Y. H. Taufiq-Yap, RSC Adv., 2014, 4, 48836-48847.
29 M. Shah, S. Ali, M. Tariq, N. Khalid, F. Ahmad and M. A. Khan, Fuel, 2014, 118, 392-397.

30 Y. B. Ren, B. Q. He, F. Yan, H. Wang, Y. Cheng, L. G. Lin, Y. H. Feng and J. X. Li, Bioresour. Technol., 2012, 113, 19-22.

31 D. E. López, J. G. Goodwin, D. A. Bruce and E. Lotero, Appl. Catal., A, 2005, 295, 97.

32 A. F. Lee, J. A. Bennett, J. C. Manayil and K. Wilson, Chem. Soc. Rev., 2014, 43, 7887-7916.

33 B. Liu, C. M. Li, G. Q. Zhang, L. F. Yan and Z. Li, New J. Chem., 2017, 41, 12231-12240.

34 F. Qin, B. Nohair, W. Shen, H. L. Xu and S. Kaliaguine, Catal. Lett., 2016, 146, 1273-1282.

35 X. M. Xiang, H. H. Zhao, J. Yang, J. Zhao, L. Yan, H. L. Song and L. J. Chou, Appl. Catal., A, 2016, 520, 140-150.

36 Z. Z. Wen, X. H. Yu, S. T. Tu, J. Y. Yan and E. Dahlquist, Bioresour. Technol., 2010, 101, 9570-9576.

37 J. M. Fraile, N. Garcia, J. A. Mayoral, E. Pires and L. Roldan, Appl. Catal., A, 2010, 387, 67-74.

38 B. M. E. Russbueldt and W. F. Hoelderich, J. Catal., 2010, 271, 290-304. 